\title{
Epidermal growth factor (EGF) and interleukin (IL)-1 $\beta$ synergistically promote ERK1/2-mediated invasive breast ductal cancer cell migration and invasion
}

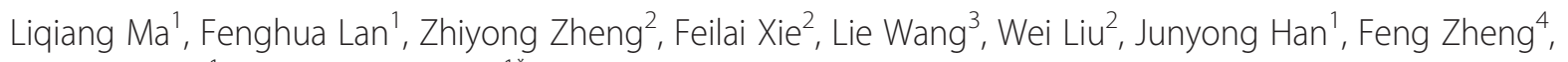
Yanchuan Xie $^{1}$ and Qiaojia Huang ${ }^{1 *}$

\begin{abstract}
Background: Patients with invasive breast ductal carcinoma (IBDC) with metastasis have a very poor prognosis. Little is known about the synergistic action of growth and inflammatory factors in IBDC metastases.

Methods: The expression of activated extracellular signal-regulated kinase1/2 (phosphorylated or p-ERK1/2) was analyzed by immunohistochemistry in IBDC tissue samples from 80 cases. BT474 IBDC cell migration and invasion were quantified using the Transwell assay. Matrix metalloproteinase (MMP)-9 expression and activity were analyzed by RT-PCR, Western blotting and zymography. Activator protein (AP)-1 activity was measured with a luciferase reporter gene assay. The Wilcoxon signed-rank test, Chi-square test, the partition of Chi-square test, independent t-test, and Spearman's method were used for the statistical analysis.

Results: Phosphorylated ERK1/2 was detected in 58/80 (72.5\%) IBDC tissues, and was associated with higher TNM stage and lymph node metastasis, but not patient age or tumor size. Individually, epidermal growth factor (EGF), and interleukin (IL)-1 $\beta$ activated ERK1/2, increased cell migration and invasion, MMP-9 expression and activity, AP-1 activation in vitro and the expression of p-ERK1/2 was positively correlated with EGF expression levels, as well as IL-1 $\beta$, MMP-9 and c-fos in IBDC tissue samples. Co-stimulation with EGF and IL-1 $\beta$ synergistically increased ERK1/2 and AP-1 activation, cell migration and invasion, and MMP-9 expression and activity. Inhibition of ERK1/2 using U0126 or siRNA abolished EGF and/or IL-1 $\beta$-induced cell migration and invasion in a dose-dependent manner.

Conclusion: Activated ERK1/2 was associated with higher TNM stage and lymph node metastasis in IBDC. Both in vitro and in vivo studies indicated that ERK-1/2 activation may increase the metastatic ability of IBDC cells. Growth and inflammatory factors synergistically induced IBDC cell migration and invasion via ERK1/2 signaling, AP-1 activation and MMP-9 upregulation.
\end{abstract}

Keywords: EGF, IL-13, ERK1/2, Invasive breast ductal carcinoma, BT-474 cells, Metastasis, MMP-9, AP-1

\footnotetext{
*Correspondence: huangqj100@126.com

${ }^{1}$ Institute for Laboratory Medicine, Fuzhou General Hospital, Second Military Medical University, 156 North Xi-er Huan Road, Fuzhou City, Fujian Province 350025, China

Full list of author information is available at the end of the article
} 


\section{Background}

Breast cancer is one of the most common malignancies in women and represents $22.9 \%$ of all female cancers worldwide [1]. Although the 5-year survival rates for breast cancer throughout the world are generally good $[1,2]$, the prognosis for patients with metastases is very poor, especially in metastatic invasive breast ductal carcinoma (IBDC). The processes by which metastasis occurs in breast cancer are still poorly understood; therefore, characterization of the precise molecular mechanisms that regulate metastasis in breast cancer could potentially result in a large reduction in the number of breast cancer deaths and may lead to novel treatments for breast cancer.

The mitogen-activated protein kinase (MAPK) signaling pathways have been widely studied, and contain at least three MAPK superfamilies that regulate diverse cellular activities. Extracellular signal-regulated kinase (ERK) is the most essential MAPK signaling pathway and is involved in cell growth, motility and survival $[3,4]$. Five ERK homologs have been identified: ERK1, ERK2, ERK5, ERK7 and ERK8 [5,6]. It is well established that ERK1 and ERK2 are two of the most important regulators of cell proliferation, growth, differentiation and migration $[7,8]$, and these processes are closely related to cancer cell progression. MAPK is activated by the upstream MAP2K kinases, which in turn are activated by the MAP3K kinases. To date, several MAP3Ks and MAP2Ks have been identified that regulate the ERK signaling pathway, including the MAP3Ks Raf and Mos, and the MAP2Ks, MAPK/ ERK kinase 1 (MEK1) and MEK2. ERK1/2 is a direct target of MEK1 and MEK2 [9].

ERK1/2 activation has been observed in a wide variety of cancers, and is closely associated with the development of human cancer and also with the migration, invasion and metastasis of cancer cells [10]. Therefore, the ERK1/2 signaling pathways are regarded as potential targets for new cancer treatments [11]. ERK1/2 is frequently activated by growth factors, such as epidermal growth factor (EGF), which leads to increased cell growth, differentiation and migration. Although the EGF/Raf/MEK1/2/ERK1/2 pathway has been investigated with respect to cancer cell metastasis, and it is known that the activation of ERK1/2 promotes the growth of breast cancer cells [12], the effect of ERK1/2 signaling activation on the metastasis of invasive breast ductal carcinoma is poorly characterized and remains of interest.

Recently, increasing attention has been paid to the tumor microenvironment, which has been closely associated with carcinogenesis and metastasis $[13,14]$. Accumulating evidence demonstrates that the cytokines secreted by tumor cells are important components of the tumor microenvironment. Interleukin (IL)-1 $\beta$ can activate ERK1/2 in several different cell types, and can also activate the transcription factor activator protein (AP)-1, which may promote inflammation-associated carcinogenesis and play a role in cancer metastasis [15]. However, the effects of ERK1/2 signaling in IL-1 $\beta$ induced inflammation-associated metastasis, and the synergistic effect of both growth and inflammatory factors on metastasis in IBDC, have not been well studied.

In this study, the roles of ERK $1 / 2$ in IBDC metastasis, and the function of EGF and IL-1 $\beta$-induced ERK1/2mediated signaling, were investigated in IBDC cells. We observed that activated phosphorylated ERK1/2 was associated with a higher TNM stage and the presence of lymph node metastasis in IBDC. Additionally, in vitro studies indicated that the activation of ERK-1/2 may increase the metastatic ability of IBDC cells, and in vivo investigations in IBDC tissue samples showed that the expression of $\mathrm{p}$-ERK1/2 had good levels of correlation with the levels of EGF in addition to IL-1 $\beta$, matrix metalloproteinase (MMP-9) and c-fos (AP-1). Growth and inflammatory factors synergistically induced IBDC cell migration and invasion via activation of the ERK1/2 signaling pathway, leading to the activation of AP-1 and increased matrix MMP-9 expression and activity.

\section{Materials and methods}

\section{Tissue samples}

The paraffin embedded blocks for 80 cases of invasive breast ductal carcinomas (IBDC) were obtained from Fuzhou General Hospital (Fuzhou, Fujian). The tissue samples were used with the consent of all patients. This study was approved by the Ethics Committee of Fuzhou General Hospital.

\section{Immunohistochemistry for phosphorylation of ERK1/2, EGF, IL-1 $\beta$, EGF plus IL-1 $\beta$, MMP-9 and c-fos}

To assess the level of ERK1/2 phosphorylation (p-ERK1/2) by using immunohistochemical detection in the 80 cases of IBDC, we used previously described methods [16], with the use of a specific anti-p-ERK1/2 antibody (1:100 dilution, Cell Signaling Company, Danvers, MA, USA). The staining results were assessed on a four-tier scale based on that described by Ju and Ebert $[17,18]$ : negative, no staining; $1+$, weak staining; $2+$, moderate staining; $3+$, strong staining. Staining intensities $\geq 1$ were considered positive. Statistical significance was evaluated by the Wilcoxon signed-rank test, Chi-square test and the partition of Chisquare test. To assess the level of EGF, IL-1 $\beta$, EGF plus IL-1 $\beta$, MMP-9 and c-fos in IBDC tissues by immunohistochemistry (IHC), we used the same method described above. Anti-MMP-9 and c-fos antibodies used for IHC were from Abcam (Cambridge, MA, USA); Anti-human IL-1 $\beta$ and EGF antibodies were from Santa Cruz (Santa Cruz, CA, USA) and Biosynthesis Biotechnology Co. 
(Beijing, China). Spearman's method was used to analyze the correlation in expression levels of p-ERK1/2 with EGF plus IL-1 $\beta$, MMP-9 or c-fos in IBDC tissue samples.

\section{Cell culture and transfection with siRNA}

BT474 cells (American Type Culture Collection, Manassas, VA) were grown in RPMI 1640 medium (Invitrogen, Carlsbad, CA, USA) containing 10\% fetal bovine serum (FBS) at $37^{\circ} \mathrm{C}$ in an incubator containing $5 \% \mathrm{CO}_{2}$. SiRNA against ERK1/2 (Cell Signaling) or control siRNA (scrambled sequence siRNA was used as nonsilencing control siRNA) (Cell Signaling) was transfected into cells with Lipofectamine 2000 according to the manufacturer's instructions.

\section{Western blotting for ERK1/2 and MMP-9}

Western blotting for the expression of ERK1/2, p-ERK1/ 2 and MMP-9 in BT474 cells was conducted using previously described methods $[19,20]$. Briefly, $12 \%$ SDSPAGE was used to detect the proteins. After the proteins were transferred onto PVDF membranes (Amersham Bioscience, Piscataway, NJ, USA) and incubated with the rabbit anti-human ERK1/2 or p-ERK1/2 (1:1,000 dilution, Cell Signaling) or mouse anti-human MMP-9 antibody (1:1,000 dilution, Abcam). The primary antibody was detected by a horseradish peroxidase-conjugated goat anti-rabbit or mouse secondary antibody (1:2,000 dilution, Santa Cruz). The immunoreactive protein bands were visualized with enhanced chemiluminescent (ECL, Amersham). Anti- $\beta$-actin (1:6,000 dilution, Sigma Company) was used as a control for the Western blots.

\section{Cell migration and invasion assay}

For the invasion assay of BT474 cells, we used methods described by Sumida et al. [21]. Millicell Hanging Cell Invasion Chambers with $8-\mu \mathrm{m}$ pore filter (Millipore Corporation) were coated with $12 \mu \mathrm{L}$ of ice-cold Matrigel (7.5 mg/mL protein; Becton Dickinson Labware, Bedford, MA). BT474 cells (50,000 per well) were added to the upper chamber of these matrigel chambers in $200 \mu \mathrm{l}$ serum-free RPMI 1640 medium with $20 \mathrm{ng} / \mathrm{ml}$ human EGF, $20 \mathrm{ng} / \mathrm{ml}$ IL-1 $\beta$ (R\&D Systems), and both or neither. Cells were then placed into 24-well plates in RPMI 1640 medium containing 10\% FBS. To evaluate the role of the U0126 inhibitor, cells were pre-treated with the reagent for $3 \mathrm{~h}$, and the stimulations were then performed. To evaluate the role of ERK1/2 siRNA in cell migration and invasion, BT474 cells were transfected with scrambled siRNA or ERK1/2 siRNA for $36 \mathrm{~h}$. Following this, the transfected cells were seeded at a density of 50,000 per well and then in $200 \mu \mathrm{l}$ of serum-free medium for the stimulation. When the 22-h incubation was completed, cells were fixed with methanol and stained with Giemsa. Cotton tips were used to remove the cells that remained in the matrigel or attached to the upper side of the filter. Light microscopy was used to count the cells on the lower side of the filter. The assays were performed in duplicate, and the results were then averaged.

The methods used for the migration assay were almost the same as for the invasion assay described above, except no matrigel was used to coat the well and the incubation time was $16 \mathrm{~h}$.

\section{RT-PCR assay}

Total RNA was extracted from BT474 cells with the Trizol reagent (Invitrogen). The expression levels of MMP-9 mRNA were detected by first reverse-transcribing the total RNA, followed by PCR with the following primers: forward, 5' - CAGTCCACCCTTGTGCTCTTC-3', reverse, $5^{\prime}$ - TGCCACCCGAGTGTAACCAT - $3^{\prime}$ for MMP9. The expression levels of GAPDH mRNA in each sample were used as controls, and primers used for amplification of GAPDH mRNA were as follows: forward, 5'-GAGTC AACGGATTTGGTCGT-3', reverse, 5' ${ }^{\prime}$-TTGATTTTGG AGGGATCTCG-3'.

\section{MMP-9 zymography assay}

MMP-9 protease activities in the concentrated supernatant medium of BT474 cells were detected by zymography. Briefly, $8 \%$ SDS-PAGE containing gelatin zymogram gels (Applygen Technologies Inc, Beijing, China.) were used to separate the proteins with electrophoresis. Renaturing and developing the gels were performed according to the manufacturer's instructions, and the gels were then stained with Coomassie blue.

\section{AP-1 luciferase reporter gene assay}

BT474 cells were transfected with AP-1 luc vector $(1 \mu \mathrm{g})$ or AP-1 luc vector plus scrambled siRNA (50-200 nM) or ERK1/2 siRNA (50-200 nM) with Lipofectamine 2000. B-gal plasmid (containing-galactosidase reporter gene) was co-transfected with AP-1 reporter plasmids to serve as the control for transfection efficiency. Thirty-six hours after transfection, the cells were left untreated or were treated with $20 \mathrm{ng} / \mathrm{ml}$ of EGF, IL-1 $\beta$ or both for 12 h. The luciferase assay (for AP-1) and enzyme assay (for $\mathrm{B}$-gal) were then performed according to the instructions of the Promega kit (Madison, WI, USA).

\section{Statistical analysis}

Statistical significance of IHC for p-ERK1/2 was evaluated by the Wilcoxon signed-ranks test, Chi-square test, and the partition of Chi-square test. Spearman's method was used to analyze the correlation in expression levels of p-ERK1/2 with EGF plus IL-1 3, MMP-9 or c-fos in IBDC tissue samples. For other experiments, values are expressed as means $\pm \mathrm{SD}$, and independent-sample t-tests were performed to determine differences among 
groups. P-values $<0.05$ were considered statistically significant.

\section{Results}

Expression of phosphorylated ERK $1 / 2$ in invasive breast ductal carcinoma

Activated ERK1/2 (p-ERK1/2) has been shown to be expressed in many different human cancers [22], and is likely to play a role in cancer cell growth and metastasis. To investigate whether p-ERK was expressed in IBDC, and to analyze the relationship between the expression of p-ERK and the clinicopathological features of IBDC, paraffin-embedded tissues from 80 cases of IBDC were examined by IHC using an antibody specific for p-ERK1/2. Positive p-ERK1/2 staining was detected in both the cytoplasm and nucleus of IBDC cells (Figure 1). p-ERK $1 / 2$ was positively expressed in $58 / 80$ cases of IBDC (72.5\%, Table 1) compared to $11 / 80$ (13.75\%) of the non-neoplastic tissues $(P<0.05$, Wilcoxon signed-rank test). The expression of p-ERK1/2 was not correlated with patient age or tumor size; however, the expression of p-ERK $1 / 2$ was closely associated with higher TNM stage and lymph node metastasis in IBDC (Table 1).

There was no significant difference in the expression of p-ERK1/2 in tumors $\geq 3 \mathrm{~cm}(23 / 33,69.7 \%)$, those sized $<3 \mathrm{~cm}$ (35/47, 74.5\%; $P>0.05$, Chi-square test), or the
A
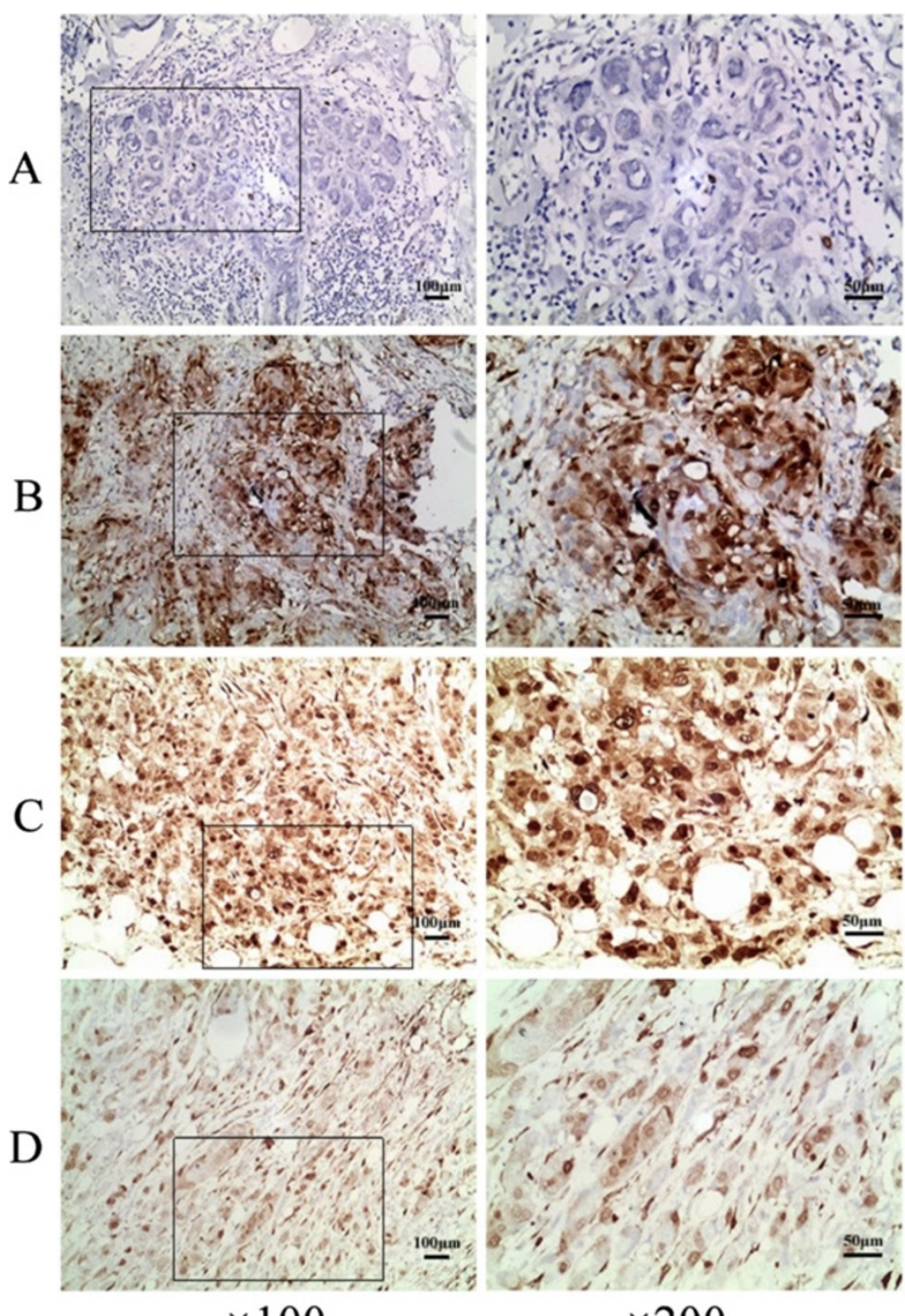

$\times 100$
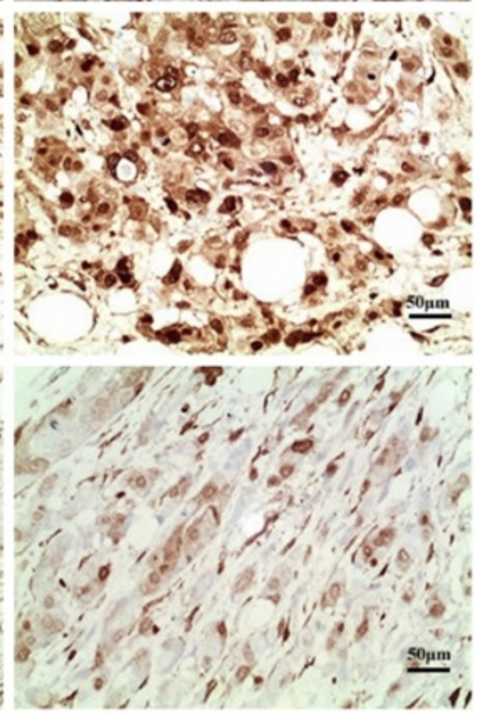

$\times 200$

Figure 1 Detection of $\mathbf{p}$-ERK1/2 expression in IBDC and non-neoplastic tissues using immunohistochemistry. P-ERK1/2 was not detected or very weakly expressed in non-neoplastic breast ductal cells (A), but was frequently expressed in both the cytoplasm and nucleus of IBDC cells (B to D). B to D represented different intensities of $\mathrm{p}$-ERK1/2 positive staining in IBDC. Images in the left panel were $\times 100$ magnification; and expanded on the right at $\times 200$. 
Table 1 Immunohistochemical detection of phosphoERK1/2 expression in invasive breast ductal cancer

\begin{tabular}{lllll}
\hline Factor & N & $\begin{array}{l}\text { p-ERK1/2 } \\
\text { positive } \\
\mathbf{n}(\%)\end{array}$ & $\begin{array}{l}\text { p-ERK1/2 } \\
\text { negative } \\
\mathbf{n}(\%)\end{array}$ & $\boldsymbol{P}$ value \\
\hline Total & 80 & $58(72.5)$ & $22(27.5)$ & $<0.05$ \\
Age & 47 & $36(76.6)$ & $11(23.4)$ & $>0.05$ \\
$<50$ & 33 & $22(66.7)$ & $11(33.3)$ & \\
$\geq 50$ & 28 & $16(57.14)$ & $12(42.86)$ & $\begin{array}{l}\text { T1:T2+T3, } \\
\text { TNM staged }\end{array}$ \\
T1 & 43 & $34(79.07)$ & $9(20.93)$ & $\mathrm{P}<0.05$ \\
T2 & 9 & $8(88.89)$ & $1(11.11)$ & \\
T3 & & & $10(30.3)$ & $>0.05$ \\
Tumor size* & 33 & $23(69.7)$ & $12(25.5)$ & \\
$\geq 3$ cm & 47 & $35(74.5)$ & & $<0.01$ \\
$<3$ cm & & & $4(9.1)$ & \\
Lymph & & & $18(50)$ & \\
node & 44 & $40(90.9)$ & $18(50)$ & \\
Positive & 36 & & & \\
Negative & & & & \\
\hline
\end{tabular}

* Tumor size was expressed as length $\times$ width; tumors with length or width $\geq 3$ $\mathrm{cm}$ were classified as $>3 \mathrm{~cm}$; tumors with both length and width $<3 \mathrm{~cm}$ were classified as $<3 \mathrm{~cm}$.

${ }^{\Delta}$ Patient with at least one positive lymph node.

tumors of patients aged $\geq 50 \mathrm{yr}(22 / 33,66.7 \%)$ or $<50 \mathrm{yr}$ (36/47, 76.6\%; $P>0.05$, Chi-square test). The expression of p-ERK1/2 varied significantly with TNM stage $(P<$ 0.05 , Chi-square test). p-ERK1/2 expression was detected in all three TNM stages, and was more frequent in stage T2 and T3 tumors than T1 tumors $(P<0.05$, partition of Chi-square test). p-ERK expression was significantly different in the tumors of patients with and without lymph node metastasis $(P<0.01$, Chi-square test), which indicated that the expression of $\mathrm{p}$-ERK $1 / 2$ correlates with metastasis and poorer prognosis in IBDC.

\section{EGF-induced ERK1/2 activation and IBDC cell migration and invasion can be attenuated by ERK1/2 siRNA or U0126}

Growth factors can activate ERK1/2, and ERK1/2 activation is closely related to cancer cell migration and invasion, which may be regulated by the upstream kinase MEK1/2 via the growth factor-induced metastasisassociated pathway [23]. Therefore, we investigated the function of the representative growth factor, EGF and ERK1/2 signaling, in IBDC cells. BT474 cells were stimulated with EGF for $30 \mathrm{~min}$. As expected, EGF-induced ERK1/2 activation was demonstrated by the detection of p-ERK $1 / 2$ in the cells (Figure $2 \mathrm{~A}$ ).

To determine whether EGF affects the migration and invasion of IBDC cells via ERK1/2 signaling, BT474 cells were treated with EGF in the presence or absence of
ERK1/2 siRNA or the MEK/ERK pathway inhibitor, U0126. The Transwell migration assay revealed that EGF increased the migration and invasion of the cells; however, EGF-induced BT474 cell migration and invasion were significantly attenuated in a dose-dependent manner by the knockdown of ERK1/2 using 50-200 nM ERK1/2 siRNA (Figures 2C, E and F). Similarly, U0126 significantly decreased EGF-induced cell migration and invasion in a dose-dependent manner (Figures 2E and F). These data strongly indicated that ERK1/2 plays an important role in growth factor-induced IBDC cell migration and invasion, and demonstrated that ERK1/2-mediated IBDC cell migration and invasion are regulated by MEK $1 / 2$.

\section{IL-1ß-induced ERK1/2 activation and IBDC cell migration and invasion can be attenuated by ERK1/2 siRNA or U0126}

It is established that inflammatory microenvironment signaling plays an important role in cancer progression, including tumor metastasis [24]. ERK1/2 are essential molecules associated with cancer metastasis. Many previous studies have focused on the role of ERK1/2 in growth factor-induced metastasis; however, ERK1/2 can also be partially activated by pro-inflammatory factors [13]. The contribution of ERK1/2 to inflammatory signal pathway-mediated metastasis has not been well studied. In order to understand the role of ERK1/2 in inflammatory factor-induced IBDC cell metastasis, BT474 cells were treated with the major cytokine IL-1 $\beta$. IL- $1 \beta$ has been reported to activate ERK1/2 in several cell types, including cancer cells $[25,26]$. As expected, IL- $1 \beta$ activated ERK1/2, as $\mathrm{p}$-ERK1/2 could be detected in BT474 cells $30 \mathrm{~min}$ after IL-1 $\beta$ stimulation (Figure $2 \mathrm{~B}$ ).

To examine the contribution of IL- $1 \beta$ to IBDC cell migration and invasion, BT474 cells were treated with or without IL-1 $\beta$. Increased cell migration and invasion were observed in cells treated with IL-1 $\beta$. Transwell assays demonstrated that knockdown of ERK1/2 expression using siRNAs attenuated IL- $1 \beta$-induced cell migration and invasion in a dose-dependent manner (Figures $2 \mathrm{E}$ and F). The MEK/ERK inhibitor U0126 also significantly inhibited IL-1 $\beta$-induced BT474 cell migration and invasion (Figures $2 \mathrm{E}$ and $\mathrm{F}$ ), indicating that IL-1 $\beta$-induced IBDC cell metastasis are dependent on the MEK/ERK signaling pathway, and also that ERK1/2 contributes to inflammatory factor-associated IBDC cell migration and invasion.

\section{EGF and IL-1 $\beta$ synergistically promote ERK1/2-mediated- IBDC cell migration and invasion}

Our results provided strong evidence to suggest that both growth factor and inflammatory factor stimulation could increase IBDC cell migration and invasion; however, it was not clear whether growth and inflammatory 
factors could exert a synergistic effect. Therefore, BT474 cells were stimulated with $20 \mathrm{ng} / \mathrm{mL}$ EGF plus $20 \mathrm{ng} / \mathrm{mL}$ IL-1 $\beta$. As shown in Figure 2D, a two to three-fold increase in p-ERK1/2 expression was detected when cells were co-stimulated with both EGF and IL-1 $\beta$, compared to either EGF, or IL-1 $\beta$ alone. Activation of ERK1/2 by EGF or IL-1 $\beta$ was almost completely blocked by ERK1/2 siRNA or the MEK/ERK pathway inhibitor U0126. Costimulation with EGF and IL-1 $\beta$ significantly increased the migration and invasion of BT474 cells by a factor of about two-fold, compared to cells treated with either EGF or IL-1 $\beta$ alone (Figures $2 \mathrm{E}$ and F). Representative light microscope images of BT474 cell migration and invasion in the Transwell assay were displayed in Figure 2G.
EGF and IL-1 $\beta$ synergistically upregulate MMP-9 in IBDC cells via the ERK1/2 pathway

Many studies have demonstrated that the upregulation of MMP-9 is associated with increased cancer cell migration and invasion [27]. To test whether MMP-9 contributes to ERK1/2-mediated IBDC cell metastasis in response to EGF or IL-1 $\beta$, RT-PCR, Western blotting and zymography assays were performed to detect the expression and activity of MMP-9 in BT474 cells. As expected, EGF increased MMP-9 expression and enzymatic activity in the cells, as demonstrated by the increased expression of $M M P-9$ mRNA, protein and disappearance of the MMP-9 substrate bands in the zymography assay. The knockdown of ERK1/2 by siRNA or the inhibition of ERK1/2 activation by U0126 significantly reduced EGF-induced MMP-9 


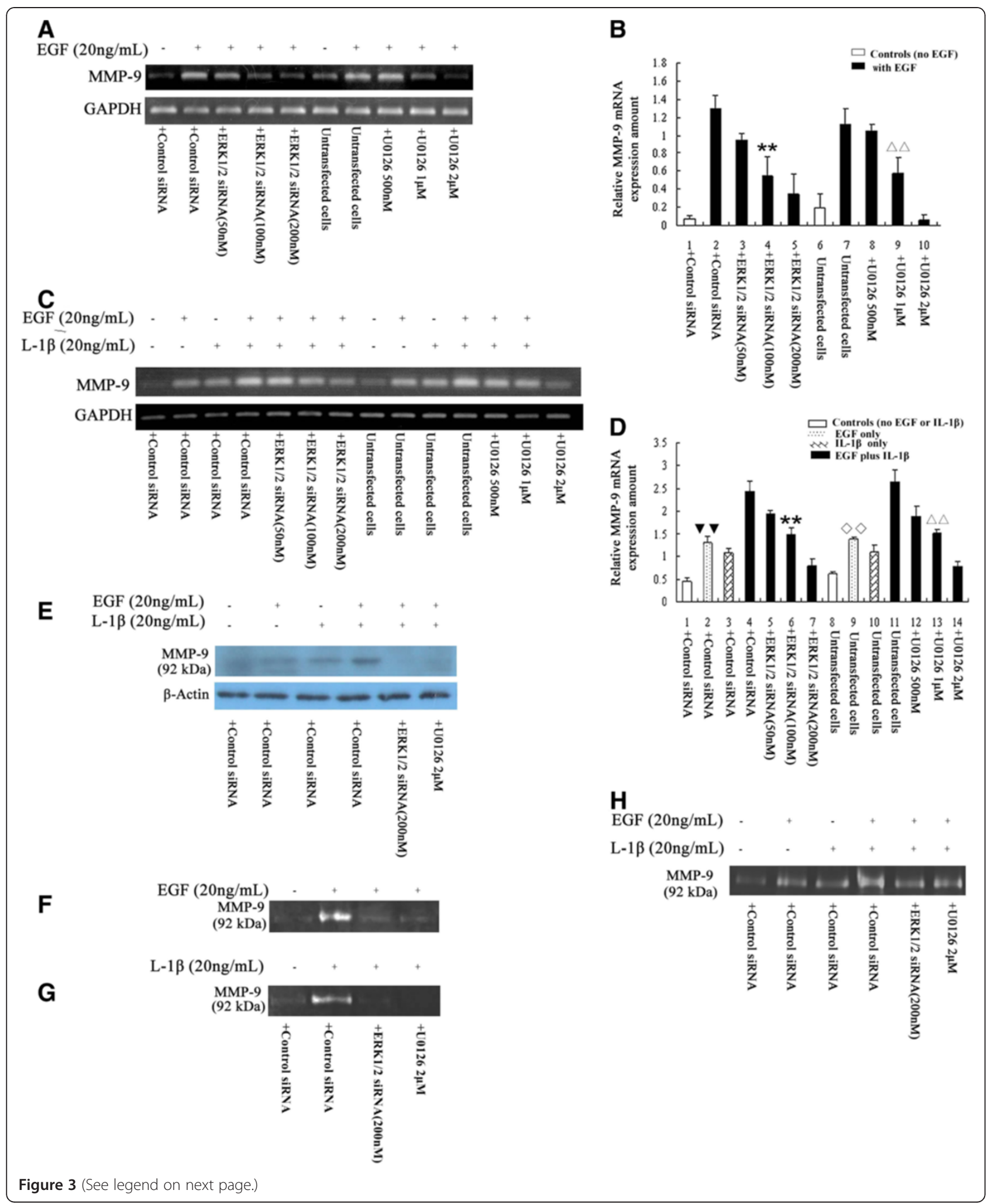


(See figure on previous page.)

Figure 3 EGF plus IL-1 $\beta$ synergistically upregulate MMP-9 in IBDC cells via the ERK1/2 pathway. A, RT-PCR showing that MMP-9 mRNA was expressed in BT474 cells and increased after EGF treatment. Knockdown of ERK1/2 using siRNA or pre-treatment with U0126 dosedependently attenuated EGF-induced MMP-9 mRNA upregulation in the cells. B, Bars indicate the relative expression levels of MMP-9 mRNA normalized to GAPDH mRNA. ${ }^{* *} P<0.05$ vs. control siRNA-transfected cells stimulated with EGF; ${ }^{\Delta} P<0.05$ vs. untransfected cells stimulated with EGF. C, IL-1 $\beta$ also increased MMP-9 mRNA expression in BT474 cells; EGF plus IL-1 3 synergistically increased MMP-9 expression compared to either EGF or IL-1 $\beta$ stimulation alone; this effect could be inhibited by ERK1/2 siRNA or pre-treatment with U0126. D, Bars indicate the relative expression levels of MMP-9 mRNA normalized to GAPDH mRNA. ${ }^{* *}$ and $\mathbf{\nabla}, P<0.05$ vs. siRNA negative control-transfected cells stimulated with EGF plus IL-1 $\beta ; \Delta \Delta$ and $\diamond \diamond, P<0.05$ vs. untransfected cells stimulated with EGF plus IL-1 $\beta$. E, EGF plus IL-1 $\beta$ synergistically increased MMP-9 expression compared to either EGF or IL-1 $\beta$ stimulation alone as analyzed by Western blotting. $\mathbf{F}$ to $\mathbf{H}$, MMP-9 activity was analyzed using zymography. F, EGF increased MMP-9 activity; this effect could be attenuated by both ERK1/2 siRNA and U0126 in the cells. G, IL-1 $\beta$ also increased MMP-9 activity in BT474 cells; H, EGF plus IL-1 $\beta$ synergistically increased MMP-9 activity compared to either EGF or IL-1 $\beta$ stimulation alone.

mRNA and protein expression in a dose-dependent manner $(P<0.05$ compared with control siRNA or untransfected cells, independent sample $t$-test), and attenuated the EGF-induced increase in MMP-9 activity (Figures 3A to $F$, and $H$, respectively). IL- $1 \beta$ alone also induced the upregulation of MMP-9 in BT474 cells; however, EGF in the presence of IL-1 $\beta$ synergistically increased both MMP-9 expression and activity by approximately 2-fold compared to EGF or IL-1 $\beta$ alone (Figures $3 \mathrm{C}$ to E, and G to $\mathrm{H})$.

\section{Knockdown of ERK1/2 inhibits the synergistic activation of activator protein-1 in IBDC cells by EGF and IL-1 $\beta$} The transcription factor activator protein-1 (AP-1) is one of the most important regulators of $M M P-9$ expression [28]. Our data showed that both EGF and IL-1 $\beta$ upregulated MMP-9, and ERK1/2 has been demonstrated to play critical role in the regulation of AP-1 activation. In order to investigate whether the synergistic mechanism by which EGF and IL-1 $\beta$ upregulated MMP9 via ERK1/2 was dependent on AP-1, AP-1 activation was detected using an AP-1 luciferase reporter gene assay. As shown in Figure 4, EGF treatment increased AP-1 luciferase activity in BT474 cells, and IL-1 $\beta$ also induced the activation of AP-1 in BT474 cells. The knockdown of ERK1/2 by siRNA significantly reduced both EGF- and IL-1 $\beta$-induced AP-1 activation in a dosedependent manner $(P<0.05$ compared with control siRNA, independent sample $t$-test). Co-stimulation with EGF and IL-1 $\beta$ synergistically increased AP-1 activity by a factor of approximately 2-fold, compared to either EGF or IL-1 $\beta$ stimulation alone (Figure 4 ), and the inhibition of ERK1/2 using siRNA reduced AP-1 reporter gene activity in cells treated with EGF plus IL-1 $\beta$. A dose-dependent decrease in AP-1 luciferase activity was detected in BT474 cells transfected with different amounts of ERK1/2 siRNA (50-200 nM) and the AP-1 luciferase reporter gene plasmid (Figure 4).

Relationship between of the expression level of p-ERK1/2, EGF plus IL-1 $\beta$, MMP-9 and AP- 1 in IBDC tissue samples In order to understand the relationship between the expression of p-ERK1/2 with proteins of interest in IBDC tissue samples, IHC was used to assay the expression of

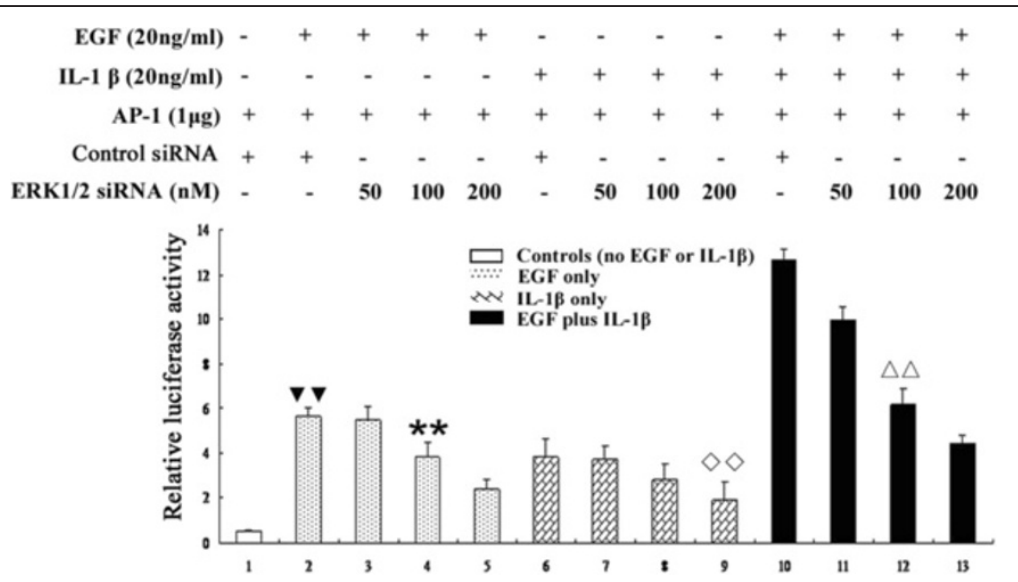

Figure 4 Knockdown of ERK1/2 inhibits the synergistic activation of AP- 1 by EGF and IL-1 $\beta$ in IBDC cells. EGF and IL-1 $\beta$ stimulation increased the activity of an AP-1 luciferase reporter gene in BT474 cells; however, EGF plus IL-1 $\beta$ synergistically increased AP-1 luciferase activity. Transfection of BT474 cells with ERK1/2 siRNA decreased EGF or IL-1 $\beta$, or EGF plus IL-1 $\beta$-induced AP-1 activation in a dose-dependent manner. ** or $\diamond \diamond, P<0.05$ vs. control siRNA and AP-1 luc-transfected cells stimulated with EGF or IL-1 $\beta$ alone; $\boldsymbol{\nabla} \nabla$ and $\Delta \Delta, P<0.05$ vs. control siRNA and AP-1 luc-transfected cells stimulated with EGF plus IL-1 $\beta$; relative luciferase activity was normalized against B-gal. 


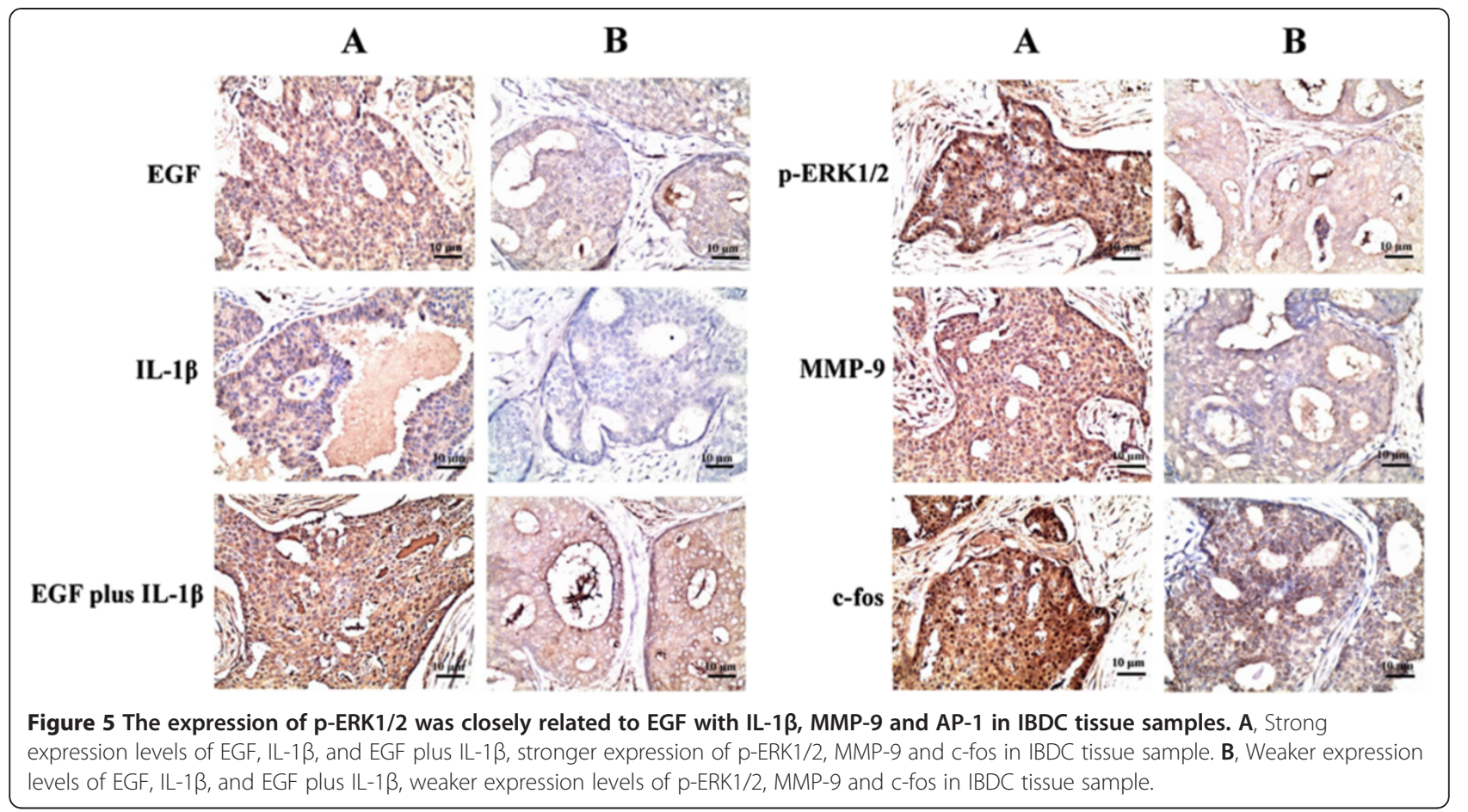

p-ERK1/2, EGF, IL-1 $\beta$ (or IL-1 $\beta$ plus EGF), MMP-9 and AP-1(c-fos). The representative IHC results from two cases of IBDC were displayed in Figure 5. As shown in Figure 5 , though the expression of $\mathrm{p}$-ERK1/2 correlated with the levels of EGF alone $(\mathrm{r}=0.638, p<0.01)$ or IL- $\beta$ alone $(\mathrm{r}=0.564, p<0.05)$, the expression of $\mathrm{p}$-ERK $1 / 2$ correlated well with levels of IL- $1 \beta$ plus EGF, in addition to MMP-9 and c-fos. There was a significant correlation between increasing p-ERK1/2 expression levels and the elevated expression of EGF plus IL-1 $\beta$, MMP-9 or c-fos in IBDC tissue samples $(\mathrm{r}=0.83$, $p<0.001 ; \mathrm{r}=0.86, p<0.001$ and $\mathrm{r}=0.77, p<0.001$, respectively). The data demonstrated that higher levels of EGF with IL-1 $\beta$ positively correlated with increased levels of p-ERK1/2, MMP-9 and c-fos expression in IBDC in vivo.

\section{Discussion}

In the present work, we demonstrate for the first time that p-ERK1/2 may be involved in the metastasis of IBDC. Additionally, growth and inflammatory factors may synergistically induce IBDC metastasis by increasing cell migration and invasion via the activation of ERK1/2 signaling, due to the AP-1-dependent upregulation of MMP-9.

ERK1/2 are important regulators of progression and metastasis in a variety of cancers via the MEK/ERK/AP1 signaling pathway $[23,28]$. However, it remains unknown as to whether ERK1/2 plays a role in IBDC metastasis. In this study, we detected the expression of activated
ERK1/2 in the majority of IBDC tissue samples using IHC assays, and found that the expression of p-ERK1/2 was closely related with a higher TNM stage and the presence of lymph node metastasis. Therefore, activated ERK1/2 may correlate with a poorer prognosis in IBDC. Karroum et al. previously reported that the expression of activated ERK1/2 was associated with cell migration and the formation of a tubular network of resistant MCF-7 breast cancer cells via a mechanism linked to the activation of MMP-9 [29].

The involvement of growth factors in cancer growth and metastasis has been widely documented. However, little is known about the role of inflammatory signaling pathways in metastasis, or the combined action of growth factors and inflammatory factors in IBDC cells. To gain an insight into the function of growth factors and inflammatory factors in IBDC metastasis, the representative growth factor, EGF, which can activate ERK1/2, and one of the most common inflammatory factors, IL-1 $\beta$, were investigated. Consistent with previous results in other cancer cell lines, EGF increased IBDC cell migration and invasion via a mechanism regulated by ERK1/2. Importantly, we also demonstrated for the first time that IL- $1 \beta$ also enhanced IBDC cell migration and invasion, and the presence of EGF and IL-1 $\beta$ synergistically increased IBDC cell migration and invasion via the ERK1/2 pathway. Therefore, ERK1/2 signaling plays an important role in inflammatory factor-associated IBDC cell migration and invasion. 
ERK1/2 is activated by MEK1/2 [30], and we confirmed that the inhibition of ERK1/2 signaling using the MEK1/2 inhibitor, U0126, or ERK1/2 siRNA significantly attenuated EGF-induced cancer cell migration and invasion in a dose-dependent manner. The breakdown of the extracellular matrix (ECM) is a crucial step during the metastatic process [31], and many studies have shown that MMPs play an important role in ECM degradation $[30,31]$. It is well known that ERK1/2 mediates cancer cell metastasis by regulating MMP-9 expression and activity. MMP-9 is one of the most important MMPs and is closely related to cancer invasion and metastasis as a result of its strong ECM proteolytic activity [27,28]. MMP-9 induces cell migration and invasion by degrading collagen in the basement membrane, which allows cancer cells to detach from the ECM and invade surrounding tissues. In this study, we demonstrated that EGF, in combination with IL- $1 \beta$, induced IBDC cell migration and invasion via the activation of ERK1/2, which increased the expression and activation of MMP-9. The role of ERK1/2 in this process was confirmed by the fact that both siRNAs against ERK1/2 and the ERK/MEK inhibitor attenuated EGF and IL-1 $\beta$-induced cell migration and invasion.

ERK1/2 is well characterized as a serine/threonine protein kinase that regulates the activation of the transcription factor, AP-1 [32]. The activation of reporter genes, as indicated by increased luciferase activity, is one characteristic of gene activation in vitro. Indeed, ERK1/2 siRNA suppressed the ability of EGF and IL-1 $\beta$ to induce activation of an AP-1 reporter gene, which demonstrated that the EGF and IL-1 $\beta$-induced activation of ERK1/2 led to the upregulation of MMP-9 by increasing the transcriptional activity of AP-1. More importantly, data from tissue samples of IBDC also confirmed that the expression of $\mathrm{p}$-ERK1/2 correlated strongly with the levels of EGF plus IL-1 $\beta$, MMP-9, and c-fos (AP-1) in vivo.

\section{Conclusions}

This study demonstrates that the expression of p-ERK1/ 2 in IBDC is closely related to lymph node metastasis and high tumor grade, which are indicative of poor patient prognosis. We also showed that ERK1/2 may functionally regulate metastasis, as growth and inflammatory factors synergistically increased IBDC cell migration and invasion via the ERK1/2 signaling pathway. This led to the activation of AP-1 and the upregulation of MMP-9. This study suggests that ERK1/2 may represent a useful therapeutic target for IBDC.

\section{Abbreviations}

ERK: Extracellular signal-regulated kinase; IBDC: Invasive breast ductal carcinomas; MAPK: Mitogen-activated protein kinase; MEK: Mitogen-activated protein kinase kinase; MMP-9: Matrix metalloproteinase-9; AP-1: Activator

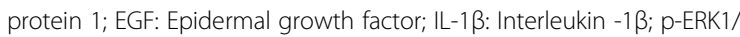
2: Phosphorylation ERK1/2; ECM: Extracellular matrix.

\section{Competing interests}

The authors declare that they have no competing interests.

\section{Authors' contributions}

LM performed the experiments and data analysis. FL participated in guiding some experiments. ZZ, FX and WL carried out immunohistochemical samples collecting and the results analysis. LW provided tissue samples and clinical data. JH performed some of the experimental studies. FZ participated in some experiment design and data analysis. YX performed some of the experiments. QH performed some experiments, and contributed to design the studies, interpret the data and write the manuscript. All authors read and approved the final manuscript.

\section{Acknowledgements}

This work was supported by the Medical Scientific Research Key Foundation of Nanjing Command (No.11Z032), the Natural Science Foundation of Fujian Province (No.2009J01181), the Medical Scientific Research Foundation of Nanjing Command (No.08 MA100) and the Fuzhou General Hospital Special Foundation (No.2004037).

\section{Author details}

${ }^{1}$ Institute for Laboratory Medicine, Fuzhou General Hospital, Second Military Medical University, 156 North Xi-er Huan Road, Fuzhou City, Fujian Province 350025, China. ${ }^{2}$ Department of Pathology, Fuzhou General Hospital, Second Military Medical University, 156 North Xi-er Huan Road, Fuzhou City, Fujian Province 350025, China. ${ }^{3}$ Department of General Surgery, Fuzhou General Hospital, Second Military Medical University, 156 North Xi-er Huan Road, Fuzhou City, Fujian Province 350025, China. ${ }^{4}$ Department of Nephrology, Fuzhou General Hospital, Second Military Medical University, 156 North Xi-er Huan Road, Fuzhou City, Fujian Province 350025, China.

Received: 7 May 2012 Accepted: 17 October 2012 Published: 21 October 2012

References

1. Jemal A, Siegel R, Ward E, Hao Y, Xu J, Murray T, Thun MJ: Cancer Statistics, 2008. CA Cancer J Clin 2008, 58:71-96.

2. Fredholm H, Eaker S, Frisell J, Holmberg L, Fredriksson I, Lindman H: Breast Cancer in Young Women: Poor Survival Despite Intensive Treatment. PLoS One 2009, 4:e7695.

3. Mebratu Y, Tesfaigzi Y: How ERK1/2 activation controls cell proliferation and cell death: Is subcellular localization the answer? Cell Cycle 2009, 8:1168-1175.

4. Balmanno K, Cook SJ: Tumour cell survival signalling by the ERK1/2 pathway. Cell Death Differ 2009, 16:368-377.

5. Abe MK, Saelzler MP, Espinosa R 3rd, Kahle KT, Hershenson MB, Le Beau MM, Rosner MR: ERK8, a new member of the mitogen-activated protein kinase family. J Biol Chem 2002, 277:16733-16743.

6. Xu YM, Zhu F, Cho YY, Carper A, Peng C, Zheng D, Yao K, Lau AT, Zykova TA, Kim HG, Bode AM, Dong Z: Extracellular signal-regulated kinase 8-mediated c-Jun phosphorylation increases tumorigenesis of human colon cancer. Cancer Res 2010, 70:3218-3227.

7. Meloche S, Pouysségur J: The ERK1/2 mitogen-activated protein kinase pathway as a master regulator of the G1- to S-phase transition. Oncogene 2007, 26:3227-3239.

8. Bai Y, Luo Y, Liu S, Zhang L, Shen K, Dong Y, Walls CD, Quilliam LA, Wells CD, Cao Y, Zhang ZY: PRL-1 protein promotes ERK1/2 and RhoA protein activation through a non-canonical interaction with the Src homology 3 domain of p115 Rho GTPase-activating protein. J Biol Chem 2011, 286:42316-42324.

9. Adams DG, Coffee RL Jr, Zhang H, Pelech S, Strack S, Wadzinski BE: Positive regulation of Raf1-MEK1/2-ERK1/2 signaling by protein serine/threonine phosphatase 2A holoenzymes. J Biol Chem 2005, 280:42644-42654

10. Park S, Jung HH, Park YH, Ahn JS, Im YH: ERK/MAPK pathways play critical roles in EGFR ligands-induced MMP1 expression. Biochem Biophys Res Commun 2011, 407:680-686. 
11. Roberts PJ, Der CJ: Targeting the Raf-MEK-ERK mitogen-activated protein kinase cascade for the treatment of cancer. Oncogene 2007, 26:3291-3310

12. Rajah TT, Peine KJ, DU N, Serret CA, Drews NR: Physiological Concentrations of Genistein and 17 $\beta$-Estradiol Inhibit MDA-MB-231 Breast Cancer Cell Growth by Increasing BAX/BCL-2 and Reducing pERK1/2. Anticancer Res 2012, 32:1181-1191.

13. Leonardi GC, Candido S, Cervello M, Nicolosi D, Raiti F, Travali S, Spandidos DA, Libra M: The tumor microenvironment in hepatocellular carcinoma. Int J Oncol 2012, 40:1733-1747.

14. Soria G, Ofri-Shahak M, Haas I, Yaal-Hahoshen N, Leider-Trejo L, LeibovichRivkin T, Weitzenfeld P, Meshel T, Shabtai E, Gutman M, Ben-Baruch A: Inflammatory mediators in breast cancer: coordinated expression of TNFa \& IL-1 $\beta$ with CCL2 \& CCL5 and effects on epithelial-tomesenchymal transition. BMC Cancer 2011, 11:130.

15. Yoshimura H, Nakahama K, Safronova O, Tanaka N, Muneta T, Morita I: Transforming growth factor-beta stimulates IL-1beta-induced monocyte chemoattractant protein-1 expression in human synovial cells via the ERK/AP-1 pathway. Inflamm Res 2006, 55:543-549.

16. Huang QJ, Huang QL, Chen WN, Wang L, Lin WS, Lin JY, Lin X: Identification of transgelin as a potential novel biomarker for gastric adenocarcinoma based on proteomics technology. J Cancer Res Clin Oncol 2008, 134:1219-1227.

17. Ebert M, Yokoyama M, Kobrin MS, Friess H, Lopez ME, Büchler MW, Johnson GR, Korc M: Induction and expression of amphiregulin in human pancreatic cancer. Cancer Res 1994, 54:3959-3962.

18. Ju XZ, Yang JM, Zhou XY, Li ZT, Wu XH: Emmprin expression as a prognostic factor in radiotherapy. Clin Cancer Res 2008, 12:494-501.

19. Huang Q, Yang J, Lin Y, Walker C, Cheng J, Liu ZG, Su B: Differential regulation of interleukin 1 receptor and Toll-like receptor signaling by MEKK3. Nat Imm 2004, 5:98-103.

20. Huang Q, Lan F, Zheng Z, Xie F, Han J, Dong L, Xie Y, Zheng F: Akt2 suppresses GAPDH mediated-apoptosis in ovarian cancer cells via phosphorylating gapdh at threonine 237 and decreasing its nuclear translocation. J Biol Chem 2011, 286:42211-42220.

21. Sumida T, Itahana $Y$, Hamakawa $H$, Desprez1 PY: Reduction of human metastatic breast cancer cell aggressiveness on introduction of either form $A$ or $B$ of the progesterone receptor and then treatment with progestins. Cancer Res 2004, 64:7886-7892.

22. Pinhel IF, Macneill FA, Hills MJ, Salter J, Detre S, A'hern R, Nerurkar A, Osin P, Smith IE, Dowsett M: Extreme loss of immunoreactive $p$-Akt and $p$-Erk1/2 during routine fixation of primary breast cancer. Breast Cancer Res 2010, $12: R 76$.

23. Furuhashi S, Sugita H, Takamori H, Horino K, Nakahara O, Okabe H, Miyake K, Tanaka H, Beppu T, Baba H: NO donor and MEK inhibitor synergistically inhibit proliferation and invasion of cancer cells. Int J Oncol 2012, 40:807-815.

24. Chen MF, Lu MS, Chen PT, Chen WC, Lin PY, Lee KD: Role of interleukin 1 beta in esophageal squamous cell carcinoma. J Mol Med (Berl) 2012, 90:89-100.

25. Arakawa T, Hayashi H, Itoh S, Takii T, Onozaki K: IL-1-induced ERK1/2 activation up-regulates p21(Waf1/Cip1) protein by inhibition of degradation via ubiquitin-independent pathway in human melanoma cells A375. Biochem Biophys Res Commun 2010, 392:369-372.

26. Angst E, Reber HA, Hines OJ, Eibl G: Mononuclear cell-derived interleukin1 beta confers chemoresistance in pancreatic cancer cells by upregulation of cyclooxygenase-2. Surgery 2008, 144:57-65.

27. Deryugina El, Quigley JP: Matrix metalloproteinases and tumor metastasis. Cancer Metastasis Rev 2006, 25:9-34.

28. Han H, Du B, Pan X, Liu J, Zhao Q, Lian X, Qian M, Liu M: CADPE Inhibits PMA-Stimulated Gastric Carcinoma Cell Invasion and Matrix Metalloproteinase-9 Expression by FAK/MEK/ERK Mediated AP-1 Activation. Mol Cancer Res 2010, 8:1477-1488.

29. Karroum A, Mirshahi P, Benabbou N, Faussat AM, Soria J, Therwath A Mirshahi M, Hatmi M: Matrix metalloproteinase-9 is required for tubular network formation and migration of resistant breast cancer cells MCF-7 through PKC and ERK1/2 signalling pathways. Cancer Lett 2010, 295:242-251.

30. Luo Y, Liang F, Zhang ZY: PRL1 promotes cell migration and invasion by increasing MMP2 and MMP9 expression through Src and ERK1/2 pathways. Biochemistry 2009, 48:1838-1846.
31. Rucci N, Sanità $P$, Angelucci A: Roles of metalloproteases in metastatic niche. Curr Mol Med 2011, 11:609-622.

32. Huang C, Ma WY, Dong Z: The extracellular-signal-regulated protein kinases (Erks) are required for UV-induced AP-1 activation in JB6 cells. Oncogene 1999, 18:2828-2835.

doi:10.1186/1476-4598-11-79

Cite this article as: Ma et al:: Epidermal growth factor (EGF) and interleukin (IL)-1 $\beta$ synergistically promote ERK1/2-mediated invasive breast ductal cancer cell migration and invasion. Molecular Cancer 2012 $11: 79$.

\section{Submit your next manuscript to BioMed Central and take full advantage of:}

- Convenient online submission

- Thorough peer review

- No space constraints or color figure charges

- Immediate publication on acceptance

- Inclusion in PubMed, CAS, Scopus and Google Scholar

- Research which is freely available for redistribution

Submit your manuscript at www.biomedcentral.com/submit
C Biomed Central 